\title{
ИЗМЕНЕНИЕ ЭКСПРЕССИОННОГО СТАТУСА ГЕНОВ ПРИ МАЛИГНИЗАЦИИ КЛЕТОК МОЗГА
}

\author{
Кит О.И. ${ }^{1}$, Пушкин А.А. ${ }^{1}$, Росторгуев Э.Е. ${ }^{1}$, Поркшеян Д.Х. ${ }^{1}$, Франциянц Е.М. ${ }^{1}$, \\ Кузнецова Н.С. ${ }^{1}$, Черкиев И.У. ${ }^{1}$, Водолажский Д.И. ${ }^{1}$
}

${ }^{1}$ Ростовский научно-исследовательский онкологический институт (РНИОИ), Ростов-на-Дону, е-таіl: опкоsekretar@mail.ru

Глиомы - наиболее распространенный тип первичных опухолей головного мозга. Они характеризуются выраженной пролиферацией и агрессивной инфильтрацией. Медианное время выживаемости пациентов с этим заболеванием составляет 16 месяцев. C использованием метода RT-PCR проведено сравнительное молекулярно-генетическое исследование паттернов транскрипционной активности 15 генетических локусов тканей глиом головного мозга у 21 пациента Юга России: EGFR, SMAD4, SMAD7, SMO, NOTCH1, NOTCH2, HBP1, HIF1A, EGLN1, EGLIN3, KDM1B, KDM1A, MSI1, MSI2, TET1. B качестве референсных использовали гены PSMC, TBP и RPLO. Экстракция препаратов суммарной РНК осуществлялась по методу P. Chomczynski и N. Sacchi. Полученные данные свидетельствуют об угнетении экспрессии локусов SMAD7, EGLN1 и EGLN3 в опухолевой ткани. Экспрессия локуса HIF1A увеличивалась. Экспрессия паттерна исследуемых генов в опухолевой ткани у пациентов с мутантным статусом генов IDH $1 / 2$ характеризовалась повышенным уровнем транскрипционной активности генов NOTCH1, NOTCH2 и EGFR. Это создаёт хорошие предпосылки для лечения таких пациентов с использованием комплекса радиационно- химической и EGFR-таргетированной терапии. Результаты исследования могут послужить основой для создания предиктивных тест-систем маркеров малигнизации и эффективной терапии глиом головного мозга.

Ключевые слова: глиома, экспрессия генов, RT-PCR

\section{CHANGE THE EXPRESSION STATUS OF GENES BY THE MALIGNISATION OF BRAIN CELLS}

Kit O.I. ${ }^{1}$, Pushkin A.A. ${ }^{1}$, Rostorguev E.E. ${ }^{1}$, Porksheyan D.K. ${ }^{1}$, Frantsiyants E.M. ${ }^{1}$, Kuznetsova N.S. ${ }^{1}$, Cherkiev I.U. ${ }^{1}$, Vodolazhskiy D.I. ${ }^{1}$

${ }^{1}$ Rostov Research Institute of Oncology, Rostov-on-Don, e-mail: onko-sekretar@mail.ru

Gliomas are the most common type of primary brain tumors. They characterize pronounced proliferation and aggressive infiltration. The median survival time of patients with this disease is 16 months. Using the RT-PCR method, a comparative molecular genetic study of patterns of transcriptional activity of 15 genetic loci of brain gliomas was conducted in 21 patients in the South of Russia: EGFR, SMAD4, SMAD7, SMO, NOTCH1, NOTCH2, HBP1, HIF1A, EGLN1, EGLIN3, KDM1B, KDM1A, MSI1, MSI2, TET1. The PSMC, TBP and RPLO genes were used as reference. The extraction of total RNA preparations was carried out by the method of $P$. Chomczynski and N. Sacchi. The obtained data testify to oppression of the expression of SMAD7, EGLN1 and EGLN3 loci in tumor tissue. The expression of the HIF1A locus increased. Expression of the pattern of the investigated genes in tumor tissue in patients with the mutant status of IDH $1 / 2$ genes was characterized by an increased level of transcription activity of the NOTCH1, NOTCH2 and EGFR genes. This study creates good prerequisites for the treatment of such patients using a complex of radiation-chemical and EGFR-targeted therapy. The results of the study can serve as a basis for the development of predictive test systems of markers of malignancy and effective therapy of brain gliomas.

Keywords: glioma, gene expression, RT-PCR

Глиомы - наиболее распространенный тип первичных опухолей головного мозга, характеризующийся выраженной пролиферацией и агрессивной инфильтрацией. Несмотря на то что хирургическая резекция, сопровождаемая комбинированной лучевой и химиотерапией, широко применяется при лечении глиом, медианное время выживаемости пациентов составляет всего лишь 16 месяцев [1]. Общая 5-летняя выживаемость составляет 
10\%. Частота встречаемости глиом различной степени дифференцировки в мире составляет 5 пациентов в год на 100000 человек [2]. Агрессивность опухолей данной нозологии обеспечивается наличием субпопуляции глиальных стволовых клеток, способных к самообновлению, инициирующих и распространяющих опухоль $[1,2]$.

Общие сигнальные пути биологии глиом включают тирозинкиназные рецепторы факторов роста и их последующий сигналлинг через каскад МАР-киназ или передачу сигналов через сигнальный путь РІ3К, утрату апоптоза, регулируемого посредством р53, нарушение регуляции клеточного цикла, стимуляцию ангиогенеза через VEGF-сигналлинг и инвазию $[1,2]$. Однако в дополнение к этим общим изменениям в различных сигнальных путях были идентифицированы также типы изменений, ряд из которых имеет прямые терапевтические последствия. К ним относится возникновение активирующих мутаций или слияний (fusion) в гене $B R A F$, наблюдаемых в пилоцитарных астроцитомах и ганглиоглиомах. В олиго-дендроглиомах наличие мутаций в генах $I D H 1 / 2$ связано с улучшенной выживаемостью при условии использования комбинированной химио- и радиационной терапии. Глиомы с низкой степенью дифференцировки разделяются на две группы, основанные на мутационном статусе генов IDH1/2: астроцитомы, развивающиеся через возникновение мутаций в генах $I D H 1 / 2$, за которыми следует возникновение мутации $p 53$, и глиомы низкого уровня и первичные глиобластомы (GBM), характеризующиеся усилением экспрессии гена $E G F R$, потерей $P T E N$ и утратой ингибиторов циклин-зависимых киназ. GBM могут быть дополнительно разделены на основе экспрессии генов и паттернов метилирования генов в три или четыре различные подгруппы. Клинически значимые прогностические маркеры в диффузных глиомах включают мутации в генах $I D H 1 / 2,1$ p/19qсочетанные делеции и метилирование промоторного участка гена $M G M T$. MGMT также является прогностическим маркером у пожилых пациентов с глиобластомой, получавших монотерапию темозоломидом $[1,2]$.

Цель нашего исследования состоит в сравнительном исследовании паттернов транскрипционной активности 15 генетических локусов в условно здоровой, опухолевой и перифокальных областях тканей головного мозга, взятых у 21 пациента с диагнозом «глиома» с наличием и отсутствием соматических мутаций в генах $I D H$ 1/2 в целях идентификации генетических локусов, в наибольшей степени ответственных за процессы малигнизации.

\section{Материалы и методы исследования}

В исследовании были использованы операционные биоптаты опухолевых тканей головного мозга, прилегающих к ним перифокальных участков (5 мм от опухоли) и немалигнизированных (условная норма) тканей, взятых у 21 пациента (63 образца) в возрасте 
36-67 лет, поступивших на лечение в ФГБУ «РНИОИ» МЗ РФ в 2017-2018 гг. Исследование было одобрено этическим комитетом ФГБУ «РНИОИ»; в каждом конкретном случае было получено добровольное информированное согласие больного на включение его в данное исследование.

Образцы для транспортировки в лабораторию и хранения мгновенно замораживали в жидком азоте без использования крио-транспортных РНК-сред. Максимальное время от момента взятия образца до его заморозки в жидком азоте составляло не более 20 с. Фрагменты ткани растирали в фарфоровых ступках в лизирующем растворе, содержащем 4 М гуанидин тиоцианат, 25 мМ цитрат натрия, 0,5\% саркозил и 0,1 M 2-меркаптоэтанол в соответствии с методом P. Chomczynski и N. Sacchi. Для удаления следов геномной ДНК полученные образцы суммарной РНК обрабатывали препаратами ДНК-азы. Синтез кДНК проводили с использованием коммерческих наборов Reverta-L («Интерлабсервис», Россия). Методом RT-qPCR определяли величины относительной экспрессии 15 генетических локусов: EGFR, SMAD4, SMAD7, SMO, NOTCH1, NOTCH2, HBP1, HIF1A, EGLN1, EGLIN3, KDM1B, KDM1A, MSI1, MSI2, TET1. В качестве референсных, после серии предварительных экспериментов, использовали гены PSMC, TBP и RPLO. Стабильность экспрессии для подбора референсных генов оценивалась с помощью программы geNorm. Дизайн специфичных олигонуклеотидных праймеров осуществлялся с использованием референсных последовательностей NCBI GenBank и программы Primer-BLAST [3].

Статистический анализ результатов выполняли с использованием пакета прикладных статистических программ Microsoft Excel 2013 (Microsoft Corporation, США) и STATISTICA 8.0 (StatSoft Inc., США). Достоверность отличий определяли с помощью непараметрического критерия Манна-Уитни. Нулевую статистическую гипотезу об отсутствии различий отвергали при пороговом уровне $\mathrm{p}<0,05$.

\section{Результаты исследования и их обсуждение}

В рамках нашего исследования 9 из 15 генетических локусов (60\%) продемонстрировали однонаправленные изменения транскрипционной активности генетических локусов в опухолевой и перифокальной зонах: SMAD4 (понижение транскрипционной активности), SMAD7 (понижение транскрипционной активности), SMO (увеличение транскрипционной активности), HBPl (понижение транскрипционной активности), HIF1A (повышение транскрипционной активности), EGLIN1 (понижение транскрипционной активности), EGLIN3 (понижение транскрипционной активности), KDM1A (повышение транскрипционной активности), MSI1 (повышение транскрипционной активности) и TET1 (понижение транскрипционной активности). Во всех остальных генетических локусах изменения транскрипционной активности исследованных 
генетических локусах в опухолевой и перифокальной областях носили противоположно направленный характер (рис. 1).

Как следует из полученных нами данных (рис. 1), в опухолевых тканях глиом общей выборки пациентов по сравнению с аналогичными неопухолевыми тканями мозга имеет место тенденция почти двукратного увеличения транскрипционной активности гена $H I F 1 A$. В этой связи необходимо отметить, что для многих глиальных опухолей характерна гипоксия c индукцией HIF, которая действует как ключевой транскрипционный модулятор, способствующий множественным процессам, ассоциированным с прогрессированием глиальных опухолей при гипоксическом стрессе, сопровождающемся ангиогенезом.

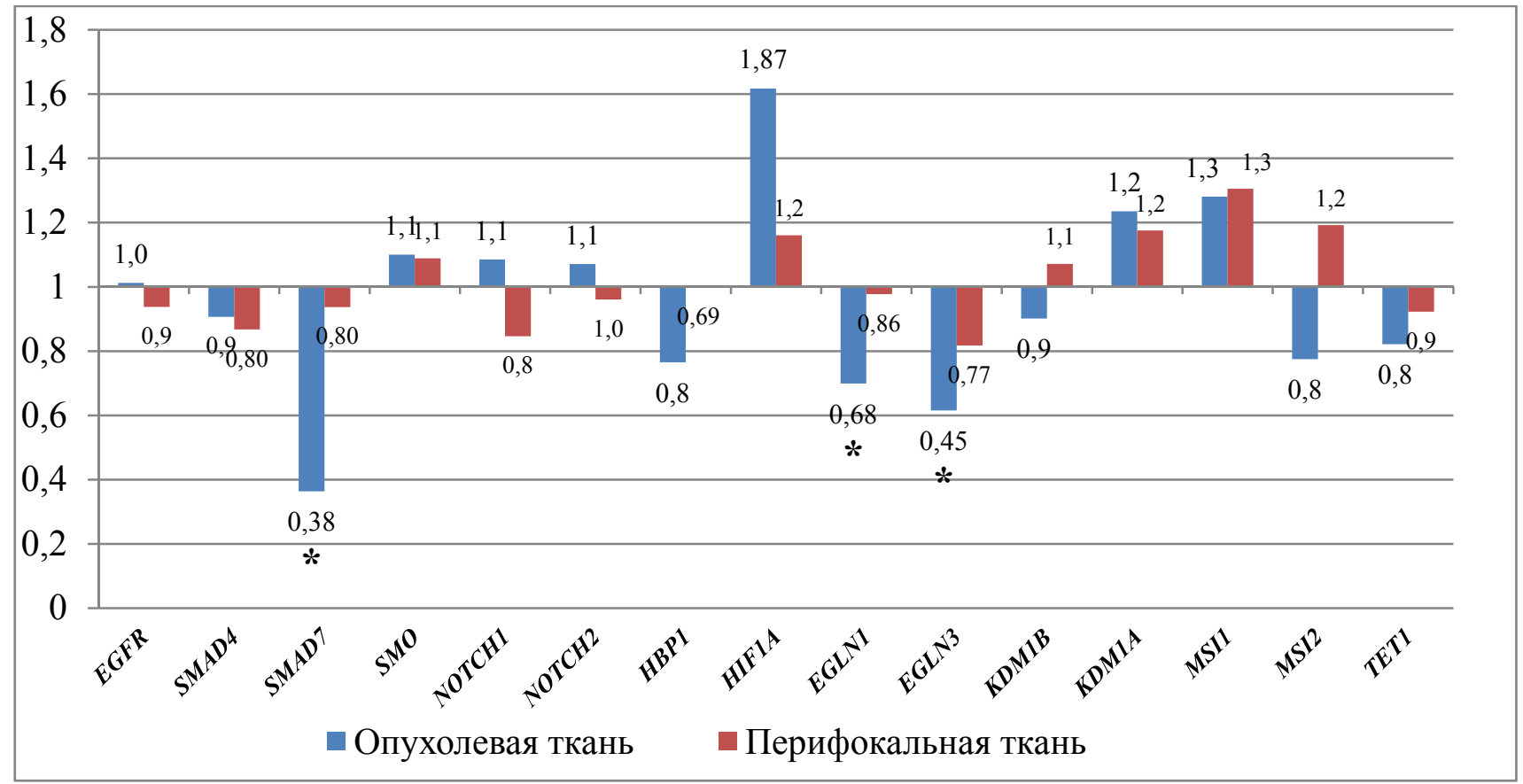

Рис. 1. Паттерн экспрессии исследуемых генов в опухолевой и перифокальной ткани относительно нормальной у пациентов с глиомами $(n=21)$.

* - статистически достоверные отличия для $p<0,05$

Поэтому разработка новых многоцелевых стратегий лечения для увеличения выживаемости пациентов $\mathrm{c}$ глиомой является современной актуальной задачей скрининговых исследований.

Продукт гена EGLN1 снижает уровень экспрессии кислород-чувствительной субъединицы фактора транскрипции HIF1A при нормоксии. EGLN1 ингибирует адаптацию клеток глиобластомы к гипоксии, регулируя экспрессию субъединиц HIF1А. Уровни транскрипции $E G L N 1$ значительно увеличиваются при гипоксии (1\% pО 2$)$, что означает, что EGLN1 является чувствительным фактором к гипоксическим условиям [1].

Экспрессия EGLN3 в опухолевой ткани мозга играет важную роль в регуляции апоптотических сигналов. Это доказывается тем, что ингибирование экспрессии EGLN3 
вызывает снижение апоптотической регуляции в клетках глиомы [4]. EGLN3 осуществляет негативную регуляцию $\mathrm{HIF}$, что препятствует приспособлению клеток опухоли к гипоксическим условиям. Было отмечено, что EGLN3 уменьшает экспрессию VEGF в опухолевых клетках и приводит к нормализации капиллярной системы. Нормализация роста сосудов путем введения ангиогенных ингибиторов становится многообещающим средством для повышения эффективности химио- и радиотерапии. EGLN3 участвует в качестве регулятора во многих фундаментальных клеточных процессах, в том числе и в регулировании роста опухолевых сосудов [5]. В наших экспериментах (рис. 1) наглядно продемонстрировано статистически достоверное (для уровня $\mathrm{p}<0,05$ ) снижение транскрипционной активности генов $E G L N 1$ и $E G L N 3$ в опухолевой ткани пациентов (в 1,5 и 2,2 раза соответственно), что свидетельствует о реакции опухолевых клеток на гипоксические условия, так как экспрессия EGLN1 и EGLN3 обратно пропорционально зависит от окружения клетки с низким парциальным напряжением кислорода. Однако в пределах данного исследования корреляционный анализ не выявил статистически значимых и достоверных ассоциаций между уровнями транскрипционной активности гена $H I F 1 A$, с одной стороны, и генами EGLN1 и $E G L N 3$, с другой стороны: $-0,11$ и $+0,24$ соответственно. Это говорит о том, что транскрипционные уровни активности этих локусов взаимосвязаны, но не имеют характера прямых линейных закономерностей. Снижение транскрипционной активности генов EGLN1 и EGLN3 обеспечивает тенденцию к повышению экспрессии гена $H I F 1 A$, так как они являются фактически его естественными негативными регуляторами [1].

В рамках данного исследования нами обнаружено статистически достоверное $(\mathrm{p}<0,05)$ снижение транскрипционной активности гена $S M A D 7$ в 2,6 раза в опухолевой ткани головного мозга относительно нормальной ткани у пациентов (рис. 1). В связи с этим необходимо отметить, что SMAD7 ингибирует передачу сигналов в сигнальном пути TGF- $\beta$, предотвращая образование комплексов $\mathrm{Smad} / \mathrm{Smad} 4$, которые инициируют передачу сигналов в сигнальном пути TGF- $\beta$ [6]. Он взаимодействует с активированным рецептором TGF- $\beta$ I типа, поэтому блокирует ассоциацию, фосфорилирование и активацию Smad2 [1]. Связываясь с рецепторами активина I типа и костного морфогенетического белка (BMP), он также играет роль в отрицательной обратной регуляции этих путей [2]. Хотя экспрессия Smad7 индуцируется TGF- $\beta$, она также индуцируется другими стимулами, такими как фактор эпидермального роста (EGF), интерферон- $\gamma$ и фактор некроза опухоли TNF- $\alpha$. Поэтому $\mathrm{Smad} 7$ обеспечивает перекрестное взаимодействие между сигнальным путем TGF- $\beta$ и другими сигнальными путями. Снижение (в 2,6 раза) экспрессии гена SMAD7 может привести к активации сигнального пути TGF- $\beta$. Как сообщалось выше, это приводит к пролиферации, ангиогенезу и развитию опухолей головного мозга. Поэтому ингибирование 
TGF- $\beta$ становится перспективной экспериментальной стратегией борьбы со злокачественными образованиями головного мозга. Доклинические исследования уже продемонстрировали мощную противоопухолевую активность ингибирования TGF- $\beta$ в сочетании с комплексной радиационно-химической терапией [7]. Оценка экспрессии SMAD7 может стать хорошим прогностическим маркером в развитии опухоли головного мозга. Изменения транскрипционной активности исследованных генетических локусов в перифокальной ткани головного мозга относительно нормальной носили существенно менее выраженный характер по сравнению с аналогичными показателями опухолевой ткани, поэтому статистически достоверного изменения экспрессии в образцах перифокальной области в рамках данного исследования не наблюдалось (рис. 1).

В подавляющем большинстве случаев (19 из 21 исследованного образца пациентов, или в 91\% случаев), соматические мутации в генах IDH1/2 в рамках проведенного нами исследования обнаружены не были (рис. 2). $I D H$-мутантные глиомы имеют отличающееся от глиом с $I D H$-дикого типа клиническое поведение. Мутантные изоформы $I D H 1$ и $I D H 2$ могут привести к развитию так называемой псевдогипоксии, т.е. к активации сигнальных путей гипоксии при нормоксии [1]. Среди эффектов мутаций IDH - истощение пула $\alpha$ кетоглутарата, необходимого для функционирования пролилгидроксилаз, и NADPH, а также накопление онкометаболита 2-гидроксиглутарата. 2-гидроксиглутарат ингибирует деметилирование ДНК, что приводит к эпигенетическим изменениям генома, которые способствуют глиомогенезу. Ингибирование пролилгидроксилаз приводит к нарушению гидроксилирования и деградации гипоксия-индуцибельного фактора HIF-1 $\alpha$, что в свою очередь приводит к индукции HIF-1 $\alpha$-таргетных генов, которые влияют на процессы ангиогенеза, роста и дифференциации, апоптоза и аутофагии [8]. Именно этот эффект и наблюдается особенно выраженно по данным нашего исследования у пациентов с мутантными типами генов IDH1 и IDH2 (рис. 2). Также у таких пациентов наблюдается значимое увеличение транскрипционной активности генов стволовости NOTCH1 и NOTCH2 почти в 2 раза. Рецепторы и лиганды NOTCH представляют собой трансмембранные белки, которые играют важную роль в момент эмбрионального и постнатального развития. Рецепторы этого семейства избыточно экспрессируются во многих видах нозологий, таких как рак поджелудочной железы, толстой кишки, рак легких и рак головного мозга [1]. Высокая экспрессия гена NOTCH1 (ID:4851) является маркером нейрональных стволовых клеток, наличие которых характерно в области мультиформной глиобластомы, они же и обеспечивают рост опухоли, резистентность к лекарственным препаратам, а также рецидив и инвазию опухоли. Инактивация экспрессии гена NOTCH1 значительно продлевает выживаемость мышей с глиомой по сравнению с контрольной группой. При опухолях мозга 
наблюдается аномально высокая экспрессия гена NOTCH2 (ID:4853), интерференция экспрессии этого гена приводит к ингибированию пролиферации клеточной линии глиомы U251 с задержкой клеточного цикла в фазе G0/G1. Полученные результаты исследований характеризуют гены NOTCH1 и NOTCH2 как потенциальные терапевтические мишени при развитии глиомы.

Также в рамках проведенного нами исследования у пациентов с наличием мутаций в генах $I D H$ 1/2 наблюдалось почти двукратное увеличение транскрипционной активности гена $E G F R$ в опухолевой ткани по сравнению с условно нормальной (рис. 2). В работе Junhong Li было проанализировано 476 публикаций по поводу влияния изменения экспрессии гена $E G F R$ при развитии глиом, среди которых были исследованы 1458 пациентов. Исследованиями Li J. и соавторов было показано, что активация транскрипционной активности гена $E G F R$ может служить полезным биомаркером для неблагоприятного прогноза и мишенью для таргетной терапии у пациентов с глиомой [9].

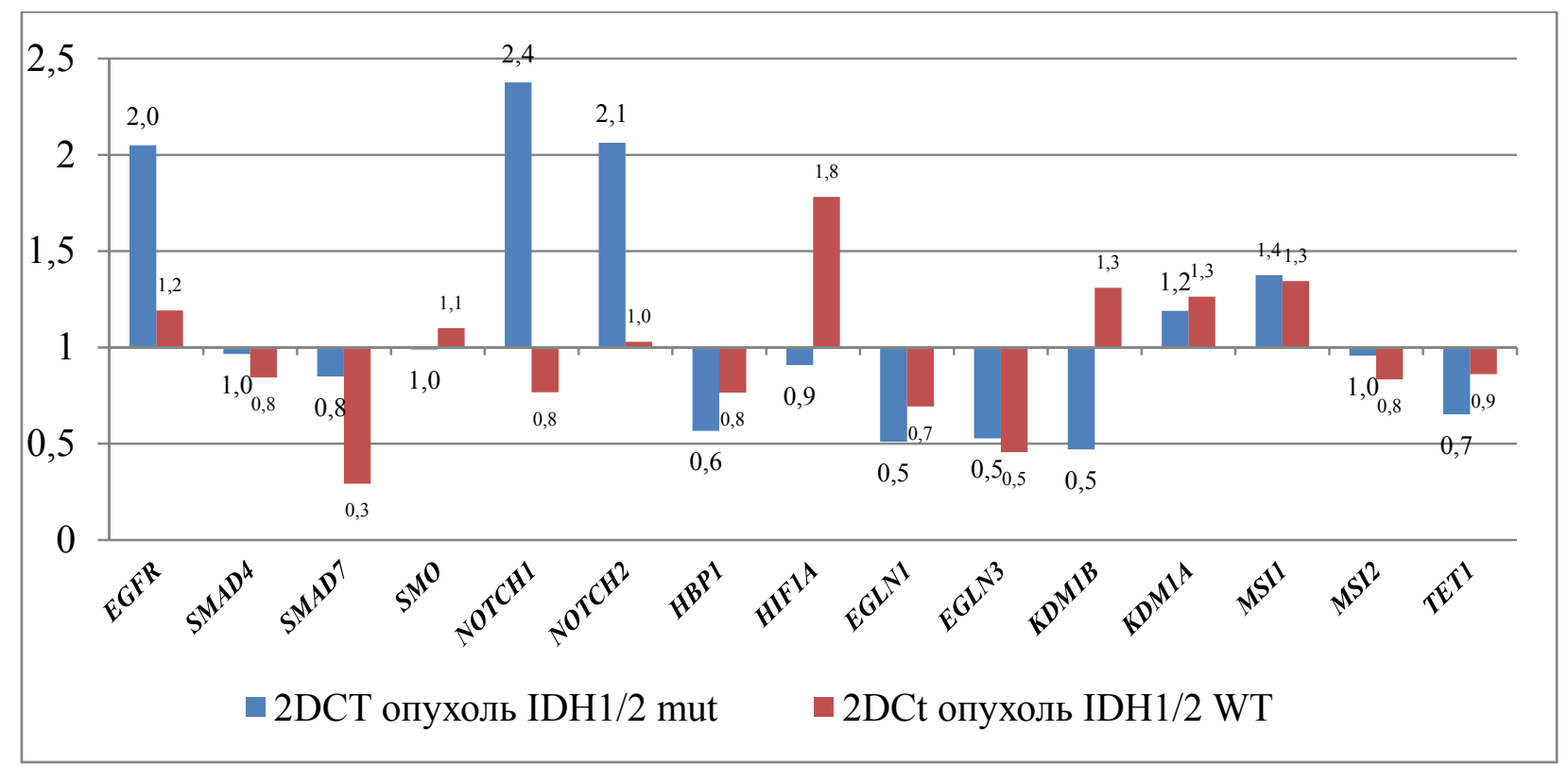

Рис. 2. Соотношение экспрессии паттерна исследуемьх генов в опухолевой и перифокальной ткани относительно нормальной у пациентов с мутантным (Mиt) и диким (WT) типами генов IDH 1/2 (n=21)

Выводы. Наши результаты дают объяснение феномена того, почему пациенты с наличием соматических мутаций в генах $I D H$ 1/2 имеют более благоприятный клинический прогноз при проведении комплексной химио- и радиационной терапии: у пациентов с наличием соматических мутаций в генах $I D H$ 1/2 имеет место повышенная экспрессия генов стволовости (NOTCH1 и NOTCH2), что обеспечивает более высокий уровень пролиферативной активности таких клеток. Также такие опухоли будут более чувствительны к использованию терапии, таргетирующей EGFR. Таким образом, проведенное исследование 
наглядно продемонстрировало понижение транскрипционной активности генов SMAD7, EGLN1 и EGLN3, а также увеличение транскрипционной активности гена HIF1A в опухолевых тканях глиом. Экспрессия паттерна исследуемых генов в опухолевой ткани у пациентов с мутантным статусом генов IDH 1/2 характеризуется повышенным уровнем транскрипционной активности генов NOTCH1, NOTCH2 и EGFR.

\section{Список литературы}

1. Кит О.И., Водолажский Д.И., Росторгуев Э.Е., Франциянц Е.М., Панина С.Б. Молекулярно-генетические маркеры глиом // Молекулярная генетика, микробиология и вирусология. 2017. № 4. С.132-140

2. Кит О.И., Водолажский Д.И., Расторгуев Э.Е., Франциянц Е.М., Поркшеян Д.Х., Панина С.Б. Мультиформная глиобластома: патогенез и молекулярные маркеры // Вопросы онкологии. 2017. № 5. С.695-702

3. Кит О.И., Водолажский Д.И., Кутилин Д.С., Никитин И.С., Моисеенко Т.И., Франциянц Е.М. Аберрантная транскрипционная активность апоптоз-регулирующих генов при малигнизации тканей тела матки // Молекулярная медицина. 2018. Т. 16. № 1. С.25-31

4. Mao K., You C., Lei D., Zhang, H. Potential regulation of glioma through the induction of apoptosis signaling via Eg1-9 family hypoxia-inducible factor 3. Oncology letters. 2017. vol.13. no.2. P.893-897

5. Sciorra V.A., Sanchez M.A., Kunibe A., Wurmser A.E. Suppression of glioma progression by Egln3. PLoS One. 2012. vol.7. no.8. P.53.

6. Xiaohua Yan, Hongwei Liao, Minzhang Cheng, Xiaojing Shi, Xia Lin, Xin-Hua Feng, and Ye-Guang Chen. Smad7 Protein Interacts with Receptor-regulated Smads (R-Smads) to Inhibit Transforming Growth Factor- $\beta$ (TGF- $\beta$ )/Smad Signaling. J Biol Chem. 2016 Jan 1. 291(1). P.382392.

7. Bogdahn U., Hau P., Stockhammer G., Venkataramana N.K., Mahapatra A.K., Suri A.A., Poverennova I. Targeted therapy for high-grade glioma with the TGF- $\beta 2$ inhibitor trabedersen: results of a randomized and controlled phase IIb study. Neuro-oncology. 2010. vol.13. no.1. P.132142.

8. Majmundar A.J., Wong W.J., Simon M.C. Hypoxia-inducible factors and the response to hypoxic stress. Mol. Cell. 2010. vol.40. no.2. P.294-309.

9. Li J., Liang R., Song C., Xiang Y., Liu Y. Prognostic significance of epidermal growth factor receptor expression in glioma patients. OncoTargets and therapy. 2018. vol.11. P.731. 